\title{
AN OBJECTIVE METHOD FOR DETERMINING CIRCULATION TIME FROM PULMONARY TO SYSTEMIC CAPILLARIES BY THE USE OF THE OXIMETER
}

\author{
BY JACK WEXLER ${ }^{1}$ AND JAMES L. WHITTENBERGER 2 WITH THE ASSISTANCE OF \\ MISS SYLVIA HIMMELFARB
}

(From the Clinical Research Section, Medical Division, Edgewood Arsenal, Maryland)

(Received for publication February 11, 1946)

Since the early work of Blumgart, Yens and Weiss ( 1 to 4$)$ many methods have been recommended for measuring the circulation time in various segments of the circulation. In general, these methods have consisted of injecting a substance into an antecubital vein and noting its arrival either at the lung, as with the ether (5) and paraldehyde (6) tests, or at some point along the systemic circulation such as the tongue, brain or carotid body. The fact that the arm to right heart circulation time varies so widely $(2,4)$ even in the normal individual constitutes a disadvantage to any test which involves the injection of a substance into the antecubital veins. Moreover, subtraction of the arm to lung time (ether, paraldehyde methods) from arm to tongue or carotid body time can give only an indirect value for the measure of the pulmonary to systemic capillary time. Another disadvantage common to many of the methods described in the literature is that the end-point is either subjective or at best not very sharp. Furthermore the end-points with some of the methods are quite unpleasant and at times alarming to the patient. The $\mathrm{CO}_{2}$ inhalation method described by Bornstein (7) in 1912 and improved by Gubner et al. (8) obviates intravenous injection and is a direct measure of pulmonary to systemic capillary time, but the fact that 2 breaths of 50 per cent $\mathrm{CO}_{2}$ are necessary raises the question as to the correct starting time for the measurement. Furthermore, the end-point which consists of stimulation of respiration and flushing of the face is not always sharp. If concentrations other than 50 per cent are used, different values for the circulation time are obtained.

In the course of employing the Millikan (9) oximeter to study the degree of arterial unsaturation during breath holding, the idea presented it-

\footnotetext{
1 Captain, M.C., A.U.S.

2 Captain, M.C., A.U.S.
}

self that a single deep inspiration of 100 per cent nitrogen might cause a sharp drop in arterial oxygen saturation and thus serve as a measure of lung to ear circulation time. Preliminary experiments justified this assumption.

The method presented in this paper measures the circulation time from the pulmonary to systemic capillaries (lung to ear) directly, by measuring the time elapsed between a single deep inspiration of 100 per cent nitrogen and the arrival at the ear of unsaturated arterial blood. The latter is noted by use of the oximeter which gives an objective end-point independent of the interpretation of the observer or subject. It was hoped that this method would afford a truer measure of the pulmonary to systemic capillary circulation segment which is the one most frequently involved in cardiovascular disease.

\section{EXPERIMENTAL}

Subjects: Thirty-five subjects varying in age from 21 to 54,10 of which were female, were used to obtain the normal range of values. The subjects were at rest but not under basal conditions during the observations. Three to 10 observations were made on each subject and the results averaged to obtain the circulation time. Three to 5 minutes elapsed between each trial.

Instruments: A 9 liter spirometer from a basal metabolism machine served as the reservoir of nitrogen. This was connected by $13 / 16^{\prime \prime}$ rubber tubing to a large caliber $\left(13 / 16^{\prime \prime}\right)$ three-way valve. The valve was fitted with a rubber mouth-piece on another arm and the third arm was in communication with room air.

The Millikan oximeter is an instrument which measures continuously the oxygen saturation of arterial blood by means of bichromatic photoelectric colorimetry of the intact fully flushed ear (9).

Procedure: Subjects were in a supine position during the period of observation. The ear unit of the oximeter was placed on the ear and the galvanometer adjusted (9). One observer manipulated the three-way valve and another watched the bell of the spirometer and the galvanometer. A nose clip was placed on the subject and he was requested to breathe room air as naturally as possible through the three-way valve. As soon as the gal- 
vanometer had stabilized (approximately 30 seconds), the subject was instructed to exhale forcibly after a normal inspiration. With the least possible delay after completion of the forced expiration, the valve was turned connecting the subject to the nitrogen reservoir and he was instructed to inhale as quickly and as deeply as he could. At the end of the forced inspiration, the valve was again turned to room air and the subject asked to resume normal respiration. Two or three practice trials generally sufficed to obtain the cooperation of the subject. One observer registered, by means of a stopwatch, the beginning of inspiration as signalled by descent of the spirometer and the start of the fall in galvanometer reading. The interval between the beginning of inspiration and the beginning of the downward deflection of the galvanometer was considered to be the circulation time. The full galvanometer deflection was noted and the test repeated when the beam had returned to its original position.

In carrying out this technique, it is important that the subject inhale quickly after maximum expiration, since prolongation of the expiratory pause will cause sufficient arterial desaturation to deflect the galvanometer and give an abnormally rapid circulation time. It is also important that the subject be requested to inspire as rapidly as possible in order to decrease the duration of inspiration to a minimum.

\section{RESULTS}

A deep breath of 100 per cent nitrogen was found to be innocuous in normal individuals and the subjects were not aware of the fact that they were breathing 100 per cent nitrogen. Most of the subjects noted a slight diminution in light perception and/or dizziness coming on several seconds after the inhalation of nitrogen and lasting for a few seconds. Electrocardiographic tracings were recorded on some of the subjects. There was a slight increase in rate during the forced expiration and a slowing immediately after the deep in-

TABLE I

Pulmonary to systemic capillary circulation times in 35 normal subjects

\begin{tabular}{|c|c|c|c|c|c|c|c|c|c|}
\hline \multirow{2}{*}{ Subject } & \multirow{2}{*}{$\operatorname{Sex}$} & \multirow{2}{*}{ Age } & \multirow{2}{*}{ Height } & \multirow{2}{*}{ Weight } & \multirow{2}{*}{$\begin{array}{c}\text { Circulation } \\
\text { time }\end{array}$} & \multirow{2}{*}{ Galv. defl. } & \multirow{2}{*}{ Vol. $\mathrm{N}_{2}$} & \multicolumn{2}{|c|}{ Pulse after inhalation $\mathrm{N}_{2}$} \\
\hline & & & & & & & & $\begin{array}{c}\text { Immedi- } \\
\text { ately }\end{array}$ & $\begin{array}{c}\text { One min. } \\
\text { later }\end{array}$ \\
\hline $\begin{array}{lr}\text { S.H. } & 1 \\
\text { A.W. } & 9 \\
\text { G.M. } & 10 \\
\text { S.F. } & 11 \\
\text { L.P. } & 13 \\
\text { D.W. } 14 \\
\text { A.K. } & 15 \\
\text { R.F. } & 16 \\
\text { P.D. } & 19 \\
\text { H.K. } & 23 \\
\text { H.T. } & 2 \\
\text { L.B. } & 3 \\
\text { A.G. } & 4 \\
\text { R.H. } & 5 \\
\text { J.W. } & 6 \\
\text { B.M. } & 7 \\
\text { B.K. } & 8 \\
\text { J.W. } & 12 \\
\text { K.V. } & 17 \\
\text { M.C. } & 18 \\
\text { C.B. } & 20 \\
\text { J.T. } & 21 \\
\text { C.C. } & 22 \\
\text { W.M. } & 24 \\
\text { O.B. } & 25 \\
\text { F.C. } & 26 \\
\text { P.D. } & 27 \\
\text { J.E. } & 28 \\
\text { I.F. } & 29 \\
\text { J.W. } & 30 \\
\text { A.D. } & 31 \\
\text { L.W. } & 32 \\
\text { C.C. } & 33 \\
\text { R.H. } & 34 \\
\text { H.T. } & 35\end{array}$ & $\begin{array}{l}\text { Female } \\
\text { Female } \\
\text { Female } \\
\text { Female } \\
\text { Female } \\
\text { Female } \\
\text { Female } \\
\text { Female } \\
\text { Female } \\
\text { Female } \\
\text { Male } \\
\text { Male } \\
\text { Male } \\
\text { Male } \\
\text { Male } \\
\text { Male } \\
\text { Male } \\
\text { Male } \\
\text { Male } \\
\text { Male } \\
\text { Male } \\
\text { Male } \\
\text { Male } \\
\text { Male } \\
\text { Male } \\
\text { Male } \\
\text { Male } \\
\text { Male } \\
\text { Male } \\
\text { Male } \\
\text { Male } \\
\text { Male } \\
\text { Male } \\
\text { Male } \\
\text { Male }\end{array}$ & $\begin{array}{l}\text { years } \\
27 \\
31 \\
21 \\
30 \\
23 \\
30 \\
29 \\
22 \\
25 \\
24 \\
30 \\
30 \\
37 \\
35 \\
31 \\
30 \\
28 \\
29 \\
28 \\
28 \\
26 \\
32 \\
33 \\
27 \\
44 \\
36 \\
34 \\
27 \\
33 \\
32 \\
32 \\
31 \\
38 \\
33 \\
54\end{array}$ & $\begin{array}{c}\text { inches } \\
60 \\
60 \\
68 \\
62 \\
62 \\
65 \\
62 \\
67 \\
65 \\
60 \\
71 \\
72 \\
69 \\
70 \\
73 \\
73 \\
69 \\
74 \\
69 \\
71 \\
71 \\
66 \\
67 \\
68 \\
66 \\
68 \\
72 \\
69 \\
68 \\
69 \\
66 \\
67 \\
71 \\
68 \\
65\end{array}$ & $\begin{array}{c}\text { pounds } \\
115 \\
112 \\
148 \\
125 \\
118 \\
130 \\
110 \\
140 \\
143 \\
99 \\
185 \\
182 \\
160 \\
165 \\
180 \\
210 \\
145 \\
175 \\
150 \\
180 \\
145 \\
148 \\
170 \\
165 \\
181 \\
160 \\
199 \\
200 \\
163 \\
160 \\
168 \\
145 \\
186 \\
142 \\
130\end{array}$ & $\begin{array}{c}\text { seconds } \\
4.9 * \\
5.2 \\
4.9 \\
5.2 \\
5.4 \\
5.2 \\
4.8 \\
4.7 \\
4.1 \\
4.3 \\
5.3 \\
6.8 \\
6.2 \\
5.8 \\
5.6 \\
\mathbf{7 . 0} \\
\mathbf{4 . 8} \\
\mathbf{5 . 1} \\
\mathbf{5 . 3} \\
\mathbf{5 . 0} \\
\mathbf{5 . 8} \\
\mathbf{6 . 5} \\
\mathbf{5 . 7} \\
\mathbf{5 . 0} \\
\mathbf{5 . 3} \\
\mathbf{6} .9 \\
\mathbf{5 . 4} \\
4.9 \\
\mathbf{5 . 2} \\
4.8 \\
\mathbf{5 . 3} \\
4.9 \\
\mathbf{4} .4 \\
\mathbf{5 . 1} \\
\mathbf{5 . 4}\end{array}$ & $\begin{array}{c}m m . \\
10 * \\
6 \\
12 \\
14 \\
15 \\
11 \\
11 \\
10 \\
10 \\
12 \\
17 \\
11 \\
7 \\
14 \\
13 \\
12 \\
11 \\
16 \\
11 \\
15 \\
14 \\
17 \\
18 \\
15 \\
12 \\
16 \\
14 \\
14 \\
12 \\
13 \\
15 \\
11 \\
13 \\
11 \\
6\end{array}$ & $\begin{array}{c}m l . \\
2220 * \\
3770 \\
2970 \\
2580 \\
2710 \\
2560 \\
3560 \\
2140 \\
3440 \\
4140 \\
5110 \\
3260 \\
4570 \\
4350 \\
3480 \\
3150 \\
4140 \\
3570 \\
5150 \\
4460 \\
3530 \\
2770 \\
3580 \\
2690 \\
4300 \\
4670 \\
4000 \\
3460 \\
4080 \\
3990 \\
3150 \\
4010 \\
3290 \\
2260\end{array}$ & $\begin{array}{r}\text { per min. } \\
744^{*} \\
95 \\
88 \\
76 \\
104 \\
86 \\
108 \\
96 \\
118 \\
\\
\\
100 \\
91 \\
\\
68 \\
86 \\
88 \\
78 \\
90 \\
84 \\
80 \\
84 \\
102 \\
92 \\
64 \\
92 \\
80 \\
78 \\
96 \\
102 \\
94 \\
98 \\
86 \\
104\end{array}$ & $\begin{array}{c}\text { per mix. } \\
70 * \\
68 \\
68 \\
64 \\
88 \\
70 \\
86 \\
88 \\
104 \\
\\
\\
88 \\
82 \\
68 \\
74 \\
76 \\
68 \\
82 \\
78 \\
70 \\
68 \\
92 \\
88 \\
58 \\
76 \\
66 \\
64 \\
80 \\
88 \\
86 \\
82 \\
76 \\
100\end{array}$ \\
\hline
\end{tabular}

* Each figure in these çolumns represents an average of 3 to 10 observations. 
spiration which lasted for about 10 seconds. These changes were missed when the pulse was recorded manually and only a slight increase in rate was noted during the first minute after the deep inspiration of nitrogen.

The results are presented in Table I and Figure 1. The circulation time for the 35 normal subjects ranged between 4.1 and 7.0 seconds with an average value of 5.2 seconds. The values for 23 or 66 per cent of the subjects were in the range of 4.6 to 5.5 seconds (Figure 1). The values for the circulation time were reproducible within a very small range in any one individual. The measurements obtained by repeated trials (3 to 10) did not differ from each other by more than 0.1 second in the most consistent individual, and by not more than 1.8 in the most variable individual. As can be seen from Table I, there was considerable variation in the average volume of nitrogen inspired by the 35 subjects, but this did not influence the sharpness of the end point or the circulation time. The average volume of nitrogen inspired per trial by 34 subjects was $3560 \mathrm{ml}$. and the average galvanometer deflection was $12.5 \mathrm{~mm}$. for the 35 subjects.

\section{DISCUSSION}

It has been shown that in normal subjects, a single inspiration of nitrogen will cause a fall in arterial blood oxygen saturation which can be recorded by the oximeter. This fact has been utilized in determining the circulation time from lung to ear. In 35 subjects without heart disease the range of values was found to be 4.1 to $7.0 \mathrm{sec}-$ onds. These values are probably higher than the true pulmonary to systemic capillary circulation time since the measurement actually includes the time of inspiration, diffusion time of the nitrogen in the residual air, the galvanometer lag and the reaction time of the observer.

Most of the methods described for determining the blood velocity in this segment of the circulation have employed two separate observations, a determination of the arm to lung circulation time by use of paraldehyde (6) or ether (5) and arm to tongue (10 to 14 ) or carotid body (4). The pulmonary to systemic capillary circulation time is then calculated by subtracting the former from the latter. Since this segment of the circulation

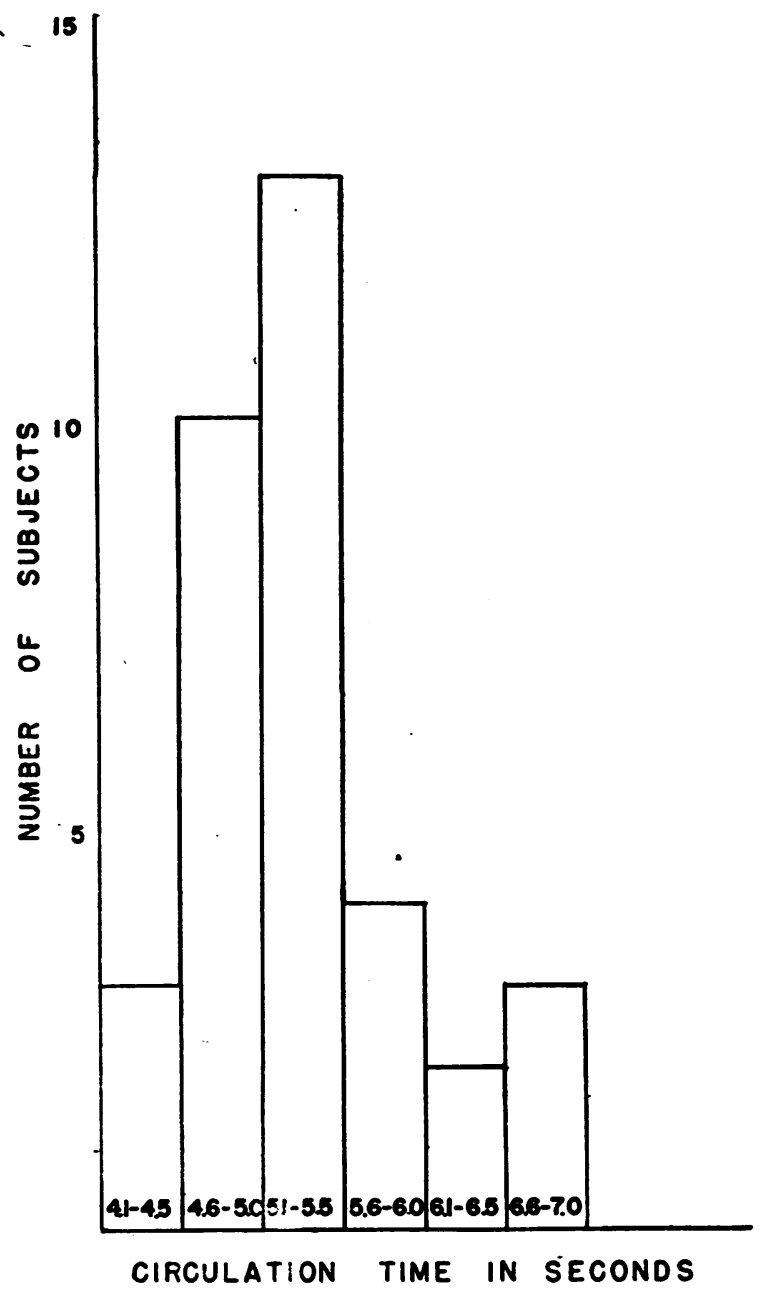

Fig. 1. Circulation Time from Pulmonary to Systemic Capillaries by the Use of the Oximeter Distribution of values obtained in 35 normal subjects.

is less variable in normals $(2,4)$, and since it is the segment most commonly affected in heart disease (failure of left ventricle), a direct method to measure the pulmonary to systemic capillary circulation time may have a special field of usefulness. The values obtained by Gubner et al. with the $\mathrm{CO}_{2}$ inhalation method (5 to 10 seconds) are higher and have a wider range than our normal values. This difference may be partially explained by the somewhat less precise end-point (stimulation of respiration and flushing of face) and the fact that two breaths of $\mathrm{CO}_{2}$ were taken and timing started from the first inspiration whereas the stimulation of respiration may have been the result of the second breath. 
The present observations suggest also that inhalation of 100 per cent oxygen might be used to measure the circulation time. Such a use might be of advantage because of the greater availability of 100 per cent oxygen, and would be particularly advantageous in patients with arterial unsaturation. However, in subjects with normal arterial saturation, the magnitude of the galvanometer deflection resulting from one deep breath of 100 per cent oxygen is too small for accurate results. It is probable that in subjects with decreased arterial saturation, inhalation of 100 per cent oxygen would give greater galvanometer deflections which would give greater assurance that a change in the reading was not due to chance. In this connection it should be pointed out that the galvanometer setting of the oximeter is arbitrary. In normal subjects, the setting is usually made to correspond to a 95 to 98 per cent arterial saturation. In patients with arterial unsaturation, the galvanometer setting would arbitrarily have to be made at 80 to 90 ; an increase in saturation resulting from a breath of pure oxygen should manifest itself by a sizeable increase in the galvanometer reading.

\section{SUM MARY}

1. A new objective method for measuring pulmonary to systemic capillary circulation time is described. It is based on the observation that a single deep breath of 100 per cent nitrogen causes a decrease in arterial oxygen saturation which can be recorded by the oximeter.

2. The advantages of this method are its objectivity, simplicity and the avoidance of the widely variable arm to heart segment of the circulation. It offers a direct procedure to test the efficiency of the left side of the heart.

3. The range in 35 normal subjects was found to be 4.1 to 7.0 seconds with an average of 5.2 seconds.

\section{BIBLIOGRAPHY}

1. Blumgart, H. L., and Yens, O. C., Studies on the velocity of blood flow. I. The method utilized. J. Clin. Invest., 1927, 4, 1.

2. Blumgart, H. L., and Weiss, S., Studies on the velocity of blood flow. II, III, IV, V, VII, VIII, IX, $\mathrm{X}, \mathrm{XI}$. The velocity of blood flow in the systemic and pulmonary circulation in health and disease. J. Clin. Invest., 1927, 4, 15, 149, 173, 199, 399, and 555 ; 1928, 5, 343, 379; and 1928, 6, 103.

3. Weiss, S., Robb, G. P., and Blumgart, H. L., The velocity of blood flow in health and disease as measured by the effect of histamine on the minute vessels. Am. Heart J., 1929, 4, 664.

4. Robb, G. P., and Weiss, S., A method for the measurement of the velocity of the pulmonary and peripheral venous blood flow in man. Am. Heart J., $1933,8,650$.

5. Hitzig, W. M., The use of ether in measuring the circulation time from the antecubital veins to the pulmonary capillaries. Am. Heart J., 1935, 10, 1080.

6. Candel, S., Determination of the normal circulation time from the antecubital veins to the pulmonary capillaries by a new technique (using paraldehyde). Ann. Int. Med., 1938, 12, 236.

7. Bornstein, A., Ueber die Messung der Kreislaufszeit in der Klink. Verhandl. d. Deutsch. Kongresses f. inn. Med. Wiesb., 1912, 29, 457.

8. Gubner, R., Schnur, S., and Crawford, J. H., The use of $\mathrm{CO}_{2}$ inhalation as a test of circulation time. J. Clin. Invest., 1939, 18, 395.

9. Millikan, G. A., The oximeter, an instrument for measuring continuously the oxygen saturation of arterial blood in man. Rev. Scient. Instruments, 1942, 13, 434.

10. Winternitz, M., Deutsch, J., and Brüll, Z., Eine klinisch brauchare Bestimmungsmethode der Blutumlaufszeit mittels Decholininjektion. Med. Klin., 1931, 27, 986.

11. Gargill, S. L., The use of sodium dehydrocholate as a clinical test of the velocity of blood flow. New England J. Med., 1933, 209, 1089.

12. Fishberg, A. M., Hitzig, W. M., and King, F. H., Measurement of circulation time with saccharin. Proc. Soc. Exper. Biol. and Med., 1933, 30, 651.

13. Goldberg, S. J., Use of calcium gluconate as a circulation time test. Am. J. M. Sc., 1936, 192, 36.

14. Bernstein, M., and Simpkins, S., The use of magnesium sulphate in the measurement of circulation time. Am. Heart J., 1939, 17, 218. 